A TUTELA JURÍDICA GLOBAL DA ALIMENTAÇÃO

\title{
GLOBAL LEGAL PROTECTION OF THE ALIMENTATION
}

Márcio Ricardo STAFFEN*

\section{RESUMO:}

O presente artigo tem como objetivo abordar o direito à alimentação como uma necessária pretensão jurídica global, não a partir da propositura de mecanismos legislativos, mas no sentido da exposição do complexo sistema de regulação/regulamentação deste direito em espaços globais, inclusive frente aos novos atores sociais identificados, bem como as novas demandas globais, às quais reclamam novas formas de proteção e equacionamento dos bens jurídicos relevantes. Isto, também, a partir da compreensão de que a satisfação das necessidades humanas primordiais, como a água e o alimento, são responsabilidades que antecedem as relações institucionais, em nível global. Inicialmente será abordado o cenário jurídico, em uma perspectiva de instrumento de contenção de excessos e projeção de expectativas realizáveis para um futuro próximo, frente ao surgimento de novas matrizes de poder. Em um segundo momento serão tecidas considerações sobre o direito à alimentação, enquanto direito inerente à toda e qualquer caracterização de Direitos Humanos e; por fim, apresentar-se-á as relações do direito à alimentação frente a complexidade do cenário jurídico global, direito este que deve ser tutelado de forma ampla e irrestrita, enquanto direito humano essencial, inclusive com a regulação do mercado transnacional concentrado e especulativo, contribuindo para o fortalecimento dos regimes democráticos e da Sustentabilidade. Utilizouse, para o desenvolvimento da presente pesquisa, o método indutivo, operacionalizado pelas técnicas de conceitos operacionais e da pesquisa bibliográfica.

\section{PALAVRAS-CHAVE:}

Direito global; Direito à alimentação; Direitos Humanos.

\footnotetext{
* Coordenador do Programa de Pós-Graduação Stricto Sensu em Direito - IMED. Professor Honorário da Faculdade de Direito e Ciências Sociais da Universidad Inca Garcilaso de la Vega (Peru). Advogado (OAB/SC) (Passo Fundo/RS/Brasil). E-mail: staffen_sc@yahoo.com.br
} 


\section{ABSTRACT:}

This article aims to address the right to food as a necessary legal global claim, not from the proposition of legislation, but towards of exposure of the complex system of regulation / regulatory of this right in global spaces, including before the new social actors identified, as well as new global demands, which require new forms of protection and equationing of relevant legal interests. This, too, from the understanding that the satisfaction of primary human needs, like water and food, are responsibilities that precede institutional relations, at the global level. Initially it will be addressed the juridical scenario, in a perspective of instrument to containment the excesses and projection of expectations possible to be performed in a near future, front the appearance of new power arrays. In a second moment considerations will be made about the right to food, as a right inherent to any characterization of Human Rights and; finally, will present the relationship of the right to food, front the complexity of the overall legal scenario, right which must be protected broadly and unrestricted, as an essential human right, including the regulation of concentrate transnational market speculative, contributing to the strengthening of democratic regimes and of Sustainability. In this study has been used the inductive method according to the technique of «operational concepts» and of bibliographic research.

\section{KEYWORDS:}

Global Law; Right to food; Human Rights.

\section{INTRODUÇÃO}

Em 09 de setembro de 1948, Ernst Reuter, então prefeito de Berlim, profere um dos discursos políticos mais impactantes da história recente. No discurso denominado "Povos do mundo, observem esta cidade!", Reuter, retrata a condição paupérrima dos habitantes da capital alemã, sobretudo, pelo bloqueio imposto pelo Exército russo, o qual deixou as já precárias condições de vida em níveis desesperadores graças ao desabastecimento de gêneros de primeira necessidade.

Contudo, o ponto que merece ganhar projeção não se restringe aos fatos históricos que se desenrolaram, mas, notadamente, pelo público que se destinou. Não obstante as R. Fac. Dir. UFG, v. 40, n.1, p. 96 - 120, jan. / jun. 2016 
milhares de pessoas que o ouviram defronte aos escombros do Parlamento, o direcionamento intencional para os indivíduos do mundo não deixa margem para maiores digressões. Há neste exemplo, uma leitura sensível e atualizada, por parte de Ernst Reuter, para compreender que determinadas pretensões jurídicas não se restringem aos Estados e organismos internacionais com que se relacionam, mas demandam a articulação com políticas globais para não se permitir o excesso de desigualdades no mundo, nem, tampouco, se restringir à indiferença de alguns êxitos nacionais diante da miséria humana em todo o território terrestre. Assim, existem pretensões que surgem e se reverberam na existência humana, sendo que o humano é eixo fundante, seu verdadeiro pressuposto.

Quando Ernst Reuter provoca os povos do mundo para que se solidarizem com os acontecimentos daqueles dias, para além da condição nacional, dos instrumentos clássicos de diplomacia ou violência, ou da bipolaridade geopolítica instalada, para fazer ecoar no humano sua súplica por alimento e água, acaba por demonstrar, no desespero das circunstâncias, aspectos de relevância ímpar para fins de ilustração da necessidade de se pensar no alimento como pretensão jurídica global, que promove cenários de exigibilidade para além das instituições nacionais ou internacionais. Melhor: que em temas de indiscutível necessidade existe uma responsabilidade humana que antecede aos vínculos institucionais e que precisa ser aperfeiçoada, historicamente, para se nos tornemos mais sensíveis com a profunda dor causada pela privação de condições básica para uma vida sadia (AQUINO, 2014).

Contudo, infelizmente a mensagem consignada nas palavras de Ernst Reuter não conseguiu lograr o êxito que merecia. A sua leitura correta dos fenômenos globalizatórios produzidos após a Segunda Guerra Mundial foi preterida pela majoritária abordagem da globalização sobre o viés econômico. Decorridos cinquenta anos dos acontecimentos retratados é que se observa uma singela inclinação para identificar na globalização uma força de globalização jurídica e dos indivíduos, mesmo que timidamente.

Como consequência, não se pode perder de vista a Expo2015, em Milão. A Expo2015, ou oficialmente Exposição Universal de 2015, inova não apenas em aspectos retóricos, mas, sobretudo, pela escolha do tema central dos debates e apresentação de soluções. Diferente dos conteúdos típicos versando sobre indústria, tecnologia, energia e afins, a edição de 2015 centraliza todas as iniciativas no tema Feeding the planet, energy for life (Alimentar o planeta, energia para a vida). Assim, é a primeira edição que aborda uma pauta comum para além dos Estados. Visa constituir um espaço dialético de enfrentamento de problemas humanitários, ambientais, sociais e econômicos, porém, mantendo o eixo 


\section{A TUTELA JURÍDICA GLOBAL DA ALIMENTAÇÃO}

gravitacional a partir dos seres humanos.

Em comum, ambos os exemplos objetivam demonstrar a relevância prática para as presentes e futuras gerações do enfrentamento das demandas alimentares em cenários globais, haja vista o enfraquecimento da centralidade dos Estados e a debilidade das Organizações Internacionais, bem como, de que essa pauta não se constitui em fato novo, pelo contrário. Para tanto, a globalização de múltiplas esferas intersubjetivas propicia a exigibilidade em nível global de pretensões pré-existentes aos vínculos artificialmente constituídos pelos Estados, como, por exemplo, o acesso à alimentação adequada.

$\mathrm{O}$ estudo que se apresenta objetiva analisar o processo de transnacionalismo e advento do direito global com foco no desenvolvimento de leituras coerentes sobre os problemas relacionados ao acesso à alimentação, nos níveis nacionais, internacionais, comunitários e transnacionais. Portanto, não se trata de escrito com o desiderato de estabelecer instrumentos legislativos clássicos de tratamento destas demandas, mas de expor o complexo sistema de regulação/regulamentação em espaços globais.

Sem embargo, todavia, não se está pela primeira vez na história a se discutir os limites, sua expansão e a implementação de bases jurídicas. Contudo, diverso do ocorrido no colonialismo americano, asiático e africano, o que se discute neste momento não é tão somente a importação e mutação de novas tradições jurídicas em espaços geográficos, físicos e políticos definidos, mas a erosão dos cenários geopolíticos habituais circunscritos apenas pelos seus interesses e necessidades.

Entretanto, o tema não se exaure somente nessa afirmação. Ao tempo em que as relações jurídicas saltaram de seus limites consolidados e tradicionais, o indivíduo em igual medida fora apresentado para novos horizontes, em decorrência das descobertas neurocientíficas, da expiação dos impulsos psicológicos, da revolução bio-médico-química e da existência em second life.

Logo, a compreensão humano-desumano/local-global, isto é, novas manifestações de poder conclamam a existência de um novo paradigma de Direito, que seja, oxalá, suficientemente herege para compreender esses novos cenários e superar os seus próprios limites. As linhas imediatas procuram justamente tratar dos paradoxos do Direito decorrentes dos fluxos globalizatórios, a partir da Ciência Jurídica, reconhecendo, de antemão, o retardo desta mirada em comparação com a Sociologia, Ciência Política ou com a Economia.

A sociedade contemporânea da globalização, da revolução tecnológica, da desterritorialização do Estado, do fenecimento das estruturas tradicionais do 
constitucionalismo desvela um tempo de grandes mudanças e transformações, as quais atingem espaços jurídicos, políticos, econômicos e até culturais. Surgem, então, novos direitos, novos atores sociais e novas demandas, as quais reclamam novas formas de equacionamento e proteção de bens juridicamente considerados relevantes.

Não por acaso se depare com uma paradoxal bifurcação de caminhos: uma época de mudança e a mudança de uma época. Utopias, valores, conceitos, ideias e práticas tradicionais acabaram por serem realocadas em novos espaços de compreensão. Uma compreensão que já não se acomoda em rótulos maniqueístas e que necessita depurar os efeitos precipitados de esquizofrenias dos referentes atribuídos à globalização ou, até mesmo, de esquizofrenias globalizatórias (universalistas). Em linhas gerais, a globalização deixou de ser uma escolha para ser um fato.

Em que pese a amplitude do debate, o artigo em comento, além do enfrentamento do direito global, estuda o direito ao alimento na perspectiva da alimentação como pretensão jurídica global, com autonomia própria no que tange ao reconhecimento estatal ou internacional, mas com condições de diálogo e coligação, bem como, a necessidade de um regime jurídico global alimentício. Razões não faltam para tanto, a saber: não se pode fechar os olhos, em analogia ao discurso de Ernst Reuter, para a caracterização do alimento como um interesse e uma necessidade sem precedentes e que condiciona a pretensão de demais bens jurídicos; que há uma relação direta entre condições adequadas de alimentação e efetiva democratização dos eixos de poder, de modo que, a ausência de segurança alimentar fragiliza qualquer regime democrático substancial, impedido o gozo de Direitos Humanos e práticas de sustentabilidade inter-geracionais.

\section{QUANDO AS PRETENSÕES JURÍDICAS SE GLOBALIZAM}

Em resumo, breve e antecipado, o Direito enquanto construção social aplicada, tem como condição primeira a procura de instrumentos de limitação dos poderes, sobretudo. Já não é mais apenas meio de ordenação social. Nessa linha de pensamento, necessita guardar em seu bojo uma perspectiva de dever-ser, de funcionalidade social. O surgimento de novas matrizes de poder exige um novo direito de contenção dos excessos e projeção de expectativas realizáveis em um futuro próximo.

Ainda que a História não tenha chegado ao seu fim, conforme profetizou 


\section{A TUTELA JURÍDICA GLOBAL DA ALIMENTAÇÃO}

Fukuyama (1992), certamente o Estado Constitucional em suas promessas liberais, sociais e democratas não foi adimplente, ao ponto de constituir mitologias jurídicas, nos dizeres de Grossi (2007). Tanto na gramática, quanto na prática várias são as disposições constitucionais que se encontram à espera de satisfação ou, que de pronto foram revogadas em face da sua (suposta) impossibilidade.

Intacto neste processo de descalcificação não restou o ordenamento jurídico. Afinal, conforme adverte Cotterrell (2006), o ordenamento jurídico não será relevante a menos que a lei (em sentindo amplo) seja capaz de produzir efeitos na sociedade. Destaque-se não tão-somente a impotência jurídica como causa deste inadimplemento, some-se neste quadro os vultos impeditivos e/ou promocionais decorrentes de condições nacionais, regionais, internacionais ${ }^{1}$, tecnológicas, sociais e, especialmente, econômicas.

Notadamente, os processos de globalização de maneira crescente criaram um mercado mundial, uma nova ordem supra e transnacional que permite a livre circulação de capitais, mercadorias, bens e serviços. Fez-se espaço para o exercício de um poder hegemônico de natureza técnico, econômico e financeiro espraiado planetariamente, o qual demonstra a redução (crise) do Estado ${ }^{2}$ e institui instrumentos de governança global. Contudo, o transnacionalismo não se restringe às fileiras de uma operação internacional arquitetada plenamente pela autonomia da vontade, inclusive na possibilidade de se escolher uma regra de direito, como pensou no início Jessup (1965). Com a mesma intensidade de aspirações por liberdades negociais, o decurso do tempo e a mensuração de práticas reais de liberdade, fez com que os indivíduos passassem a reclamar igual parcela de liberdade.

Com clareza ímpar se vislumbra nos dizeres de Gomes Canotilho o ataque contínuo ao estatalismo centralizador e unitário de inspiração hegeliana. Ao tempo em que a ausência de um Estado europeu não é, via articulações silogísticas, empecilho para a aprovação de uma Constituição da União Europeia, não é, por si só, travejamento para o desenvolvimento de um direito global (CANOTILHO, 2008, p. 202-203). O Estado perdeu sua habilitação de único senhor da ordem (ARNAUD, 2007, p. 3).

Queste connessioni, combinandosi con imponenti flussi migratori, determinano un progressivo superamento dei confini statali che, affrancando le Costituzioni dal territorio (Zagrebelsky), cioè deterritorializzando la sovranità, genera la consapevolezza che ciascuno Stato non dispone più degli strumenti normativi per soddisfare da solo i bisogni dei suoi cittadini, il loro benessere e la loro salute minacciata dai cibi transgenici, dai virus e dalle radiazioni che vengono da lontano. (REPOSO, 2009, p. 26). 
A partir da fragilidade dos tradicionais atores nacionais, espaços de debilidade passa(ra)m a serem ocupados, notadamente após a Segunda Guerra, por interesses transnacionais constituídos por meio de instituições novas, de difícil caracterização a partir do glossário político-jurídico Moderno (STAFFEN; BODNAR; e CRUZ, 2011). A tradicional homogeneidade no pensamento político-jurídico fora perdida. Em maior ou menor medida, instalou-se um cenário de tensão institucional, no qual as "velhas" instituições estatais e, por via idêntica os indivíduos, deparam-se com sensações de turbulência (GIUDICE, 2011).

Tal qual se manifestou Teubner (2004), a força motriz do Direito já não é mais os anseios de limitação jurídica dos poderes domésticos absolutos; mas, sobremodo, a regulação de dinâmicas policêntricas relacionadas com a circulação de modelos, capitais, pessoas e instituições em espaços físicos e virtuais. Nessa medida, necessário se faz reconsiderar as relações existentes entre Direito e Estado, entre público e privado, entre os diferentes cenários jurídicos e as autoridades legais, sob pena da exaustão dos modelos decorrentes de fraturas infindáveis. É preciso ter essa clareza: as relações e responsabilidades humanas não gravitam, nem se prendem, apenas nos contornos territoriais do Estado-nação, mas caminham, de modo transfronteiriço, para outros horizontes de integração e convivência.

Nestes termos, o declínio do Estado Constitucional nacional e a ascensão de um paradigma global de Direito decorre, substancialmente, da penetração de critérios de governança nos assuntos e políticas públicas dos Estados, logisticamente apoiado pelos avanços tecnológicos. A globalização econômica produz um processo de globalização ${ }^{3}$ jurídica por via reflexa, que transcende a constatação de Crouch, uma vez que se observa em igual medida a globalização também dos comportamentos jurídicos.

Assim, o processo de globalização necessita ser compreendido como expressão de uma interdisciplinaridade sistêmica (COTTORRELL, 2012). Logo, o Direito Global, por mais incipiente que seja, tem como objeto a compreensão e a regulação das relações provenientes dos fluxos globalizatórios. Fluxos estes que não se restringem à globalização do segundo pósguerra. Contudo, ainda que algumas bases de governar o mundo estejam sedimentadas na descoberta da América, a grande especificidade verte da policentricidade que governa a globalização do terceiro milênio.

Notadamente entre 1980 e 1990, a caracterização da concepção habitual de governo é transladada para a acepção governança (governance), a partir dos postulados de Rosenau e Czempiel (1992), haja vista a combinação de instituições, políticas e iniciativas conjuntas com propósitos claros e definidos. A partir desse cenário, o problema de governar o 


\section{A TUTELA JURÍDICA GLOBAL DA ALIMENTAÇÃO}

mundo se funde em contextos que perpassam por alianças militares (OTAN); instituições intergovernamentais (ONU, UNESCO, UNICEF, FAO, OMC, OMS e afins); organismos regionais (Conselho Europeu); agremiações pós-imperialistas (Commonwealth, Comunidade dos Países de Língua Portuguesa); ordenamentos quase políticos (União Europeia, Mercosul, UNASUL); summit (G-20, G-8, BRICS) e outras milhares de ONGs.

Ainda que o fenômeno da globalização não se mostre uma novidade, certamente a crise econômica vivida em 2008, demonstrou substancialmente os diversos níveis de marcha deste processo de expansão. Notadamente, a economia se globaliza com maior velocidade, em comparação com a política (e com os assuntos do Estado), criando, neste panorama, assimetrias entre economia global (transnacional) e a política nacional (não se podendo descartar a política comunitária).

Para Snyder (1999), a globalização é governada pela totalidade de conjunções estrategicamente determinadas, contextualmente específicas e frequentemente episódicas, irradiadas de diversos lugares pelo mundo, com elementos institucionais, normativos e processuais específicos, mas não necessariamente exclusivos. Procede-se, nestes termos, a uma forma global de pluralismo jurídico (SNYDER, 1999, p. 334). Um pluralismo que não é unitário nem uniforme; não é orgânico nem estruturado.

Este diagnóstico representa exatamente o exaurimento do Estado e das instituições internacionais de cunho monista-dualista. As vertentes do Direito Global articulam-se em múltiplos níveis, governos, administrações locais, instituições intergovernamentais, cortes ultra-estatais e nacionais, networks, organismos híbridos (público-privado), organizações nãogovernamentais e dos próprios indivíduos.

\footnotetext{
Esse novo paradigma jurídico permeia os tecidos normativos estatais, utilizando os canais que a própria globalização cria (in primis aqueles econômicos e judiciários) e subtraindo soberania às instituições "tradicionais". É a "linguagem dos interesses", portanto, a fazer com que a fronteira entre hard Law (Constituição, leis, etc.) e soft Law (antecedentes judiciários, "programas de ajuste estrutural das finanças do Estado", etc.) se torne sempre mais sutil e irrelevante. A linguagem normativa transnacional se declara mais como motor de "convergências" e de "diálogos" que de diferenças: a retórica do cosmopolitismo esconde a conotação imperativa do direito global, aproveitando-se da ausência de um aparato de poderes públicos ao qual atribuir a função coercitiva e da presumida posição de igualdade dos sujeitos jurídicos. (OLIVIERO; CRUZ, 2012).
}

Estas instituições intergovernativas, pelas quais os Estados buscam maior legitimidade e meios de promoção de políticas públicas, classificam-se nas seguintes categorias, segundo argumentação de Kingsbury, Kirsch e Stewart:

R. Fac. Dir. UFG, v. 40, n.1, p. 96 - 120, jan. / jun. 2016 
[...] administration by formal international organizations; administration based on collective action by transnational networks of governmental officials; distributed administration conducted by national regulators under treaty regimes, mutual recognition arrangements or cooperative standards; administration by hybrid intergovernmental-private arrangements; and administration by private institutions with regulatory functions. (2005, p. 20).

Todavia, a existência de um direito global alimenta, nesta quadra da História, uma pluralidade de desafios, a iniciar pelas próprias bases de globalização, múltipla em sua essência. Ao passo que a globalização guarda vastidão de caráteres, tais signos observam-se também nos ordenamentos jurídicos, nacionais e os sistemas transnacionais. Há um forte problema decorrente do conflito entre uniformidade global e diferenças nacionais (locais), da concorrência entre normas globais, normas nacionais e normas locais, vide o caso Myanmar vs. OIT e Banco Mundial vs. Índia, da identificação do juiz competente para conhecer/decidir sobre a pretensão resistida, seja nacional ou global.

O poderio dos ordenamentos jurídicos estatais de produzir o próprio Direito em forma absoluta está gradualmente se redimensionando, reformulando a própria categoria histórica e política da soberania nacional na direção de uma caracterização ainda de híbrida matriz. O Direito Global está dividido em dois níveis: o primeiro - e mais raso - que se preocupa com os assuntos nacionais (internos) de cada Estado; e o segundo, mais amplo, diluído no cenário transnacional, constituído por uma área global (CASSESE, 2006) ${ }^{4}$, de modo que predomine a cooperação (partnership) entre seus agentes em seu duplo nível.

La prima condizione della sua stessa esistenza e del suo funzionamento, è il
tranznazionalismo. L'ordine giuridico globale, mentre viene descritto normalmente
come costruito lungo linee verticali - dal livello nazionale a quello globale - è,
invece, di fato, costruito innanzitutto da linee orizzontali, trà autorità nazionali e
agenzie globali e tra agenzie globali. In altre parole, è un ordinamento fondato
largamente sulla cooperazione sia al livello interstatale, sia al livello globale in senso
stretto. (CASSESE, 2006, P. 11).

Este cenário de cooperação absolutamente novo em suas características pode ser facilmente ilustrado nos exemplos da Organização Internacional para a Estandardização (ISO), composta por organismos de normatização, de matriz híbrida público-privado, criando pontes entre setores públicos e privados, mas, com atribuições, regulamentadoras iminentemente públicas (SCHEPEL, 2005). O mesmo critério de parceria se vislumbra com a aderência de Estados ao Comitê da Basiléia para vigilância bancária, de modo que uma instituição tipicamente nacional transcende sua prima ratio para contribuir com autoridades bancárias internacionais. Todavia, conforme já antecipado, o caso de maior envergadura e R. Fac. Dir. UFG, v. 40, n.1, p. 96 - 120, jan. / jun. 2016 


\section{A TUTELA JURÍDICA GLOBAL DA ALIMENTAÇÃO}

incidência prática no dia-a-dia aponta para a regulamentação e regulação da internet. Cabe à ICANN - Internet Corporation for Assigned Names and Numbers, uma organização públicoprivada, composta por entes privados desenvolver funções públicas que atingem o globo indistintamente. Especificamente ao tema do direito à alimentação importante destacar a função exercida com liderança pela OMC, com apoio da FAO, OMS para implementação de Sistemas Nacionais de Controle Alimentar (SNCA) e estruturação do Codex Alimentarius (MARICHAL, 2014).

$\mathrm{Na}$ mesma toada, por sua vez, existem organizações estritamente privadas a transitarem no cenário global sem pontos de dependência e condicionantes público-estatais. É o caso da Federação Internacional de Futebol Associado (FIFA) e da Câmara Internacional de Comércio (ICC) que elabora e aplica suas normas de modo autônomo com o objetivo central de promover o comércio e investimentos internacionais, servindo, inclusive, de instituição parceira para organismos nacionais e internacionais, conforme se vislumbra com a ONU e com a OMC (CASSESE, 2013, p. 19).

Ademais, observa-se uma progressiva majoração de organizações privadas na tratativa de assuntos globais, com gerência regulamentadora e reguladora, nas mais diversas áreas de incidência e de competência material. Tratam-se de entes originariamente privados, sem vínculos governamentais, que se dedicam à proteção ambiental, ao controle da pesca, à fruição dos direitos sobre à água, aos alimentos, à segurança alimentar, às finanças e ao comércio, à internet, aos fármacos, à tutela da propriedade intelectual, à proteção de refugiados, à certificação de insumos quanto à procedência, à preservação da concorrência, ao controle de armas e combate ao terrorismo, ao transporte aéreo e naval, aos serviços postais, às telecomunicações, à energia nuclear e seus resíduos, à instrução, à imigração, à saúde e ao esporte.

Formam-se, assim, sistemas jurídicos globais parciais (TEUBNER, 2005), isto é, buscam estabelecer diretrizes válidas em níveis globais, sem, contudo, objetivar regulamentar a integralidade das relações sociais, de modo que consegui instituir um núcleo legítimo e válido para cada espaço de normatização. Na percepção de Cassese, o que se vislumbra é a construção de regime regulador para os processos de globalização sustentado pela chamada "ad-hoc-cracia" (2013, p. 22), isto é, um encadeamento de normas setoriais relativas às matérias singulares ao caso, na maioria das vezes, que gravitam por vazios normativos no complexo global (composto por normas transnacionais, supranacionais, nacionais e regionais). 
Eis outra razão para se mirar no atual contexto uma realocação dos critérios jurídicos que regiram o modelo estamental/feudal que norteou as relações estatais no medievo. Aos Estados o monopólio da força em seus territórios com subtração dos aspectos habituais da soberania. Nestes termos, a dimensão global do Direito não busca promover a erradicação do Estado e de seus espaços de governo. Não lhe interessa também um encadeamento vertical dos entes. Todavia, o que se percebe é a real impossibilidade de cisões entre espaços nacionais, internacionais e transnacionais, como se pretendeu articular no passado com a díade nacional-internacional. A causa central desta projeção é a indiscutível capacidade reinante nas organizações provenientes dos fluxos globalizatórios de se relacionarem diretamente com os sujeitos e com a sociedade civil, sem perpassar estâncias oficiais de poderes.

Promove-se, destarte, o cambiamento do modo tradicional de pensamento das instituições para um contexto de conectividade horizontal dos sistemas jurídicos, criando linkages, (LEEBRON, 2002, p. 05) um paradigma suportado pela credibilidade em networks, verdadeiro regime complex. Por consequência, em definitivo deixa de ser importante o foco no divórcio entre o público e o privado, em virtude da dinâmica motriz impulsionadora.

Todavia, renasce frequentemente a inquirição sobre os instrumentos de respeito às normas, afinal no campo doméstico (nacional) impera a definitividade das decisões e a soberania decorrente do exercício legitimo da força pelo poder, contudo, os cenários transnacionais não gozam desta prerrogativa. Assim, como consequência deste panorama de linkages o que se observa é a observância das normas através de instrumentos de indução e substituição, de modo que conteúdos jurídicos estanques são incluídos em pautas combinadas, isto é, a temática dos alimentos, por exemplo, já não se inscreve apenas pela tutela pura de Direitos Humanos, mas também em expedientes outrora tipicamente negociais e comerciais. Além disso, os Estados passam a se sujeitarem aos expedientes globais no intuito de reduzir chances de retaliações e denúncias com consequências perniciosas e de difícil contenção.

Em igual medida, a leitura possível de ser feita sobre os atuais panoramas desvela a compreensão clara de que o ideal de Direitos Humanos se apresenta como indivisível, de modo que a globalização não está autorizada a fraciona-lo. Ao reverso, o reconhecimento de pretensões jurídicas globais justificadas subsidia a globalização dos Direitos Humanos e sua exigibilidade em múltiplos níveis. 


\section{A TUTELA JURÍDICA GLOBAL DA ALIMENTAÇÃO}

\section{DIREITO AO ALIMENTO}

\subsection{Alimento Como Bem Jurídico Global}

Em que pese todo o processo de evolução dos Direitos Humanos, bem como seu critério fundante ${ }^{5}$, importante destacar nesta quadra que o reconhecimento jurídico do direito à alimentação apresenta-se como inerente a toda e qualquer caracterização de Direitos Humanos. Mesmo que se persista na divisão tópica dos Direitos Humanos em estratos para uma (suposta) melhorar caracterização, em virtude de seu desenvolvimento histórico e ações que demandam por sua adimplência, o que já restou vergastado por sua debilidade prática, a garantia de alimentação adequada, consignada no art. 22-5, da Declaração Universal de Direitos Humanos, é pauta comum para dimensões liberais, sociais, econômicas e culturais.

Paralelamente, não se pode perder de vista a total pertinência do direito à alimentação adequada, na dimensão primeira dos Objetivos de Desenvolvimento do Milênio, colacionados pelo Programa das Nações Unidas para o Desenvolvimento. Não por acaso, além da condição preliminar, sua representação iconográfica se dá pelo desenho de um prato cheio, fundo e quente.

Ainda que a consideração de direito fundante recaia sobre o direito à vida, o que necessita ser equalizado com o tratamento jurídico dispensado à dignidade da pessoa humana, maiores dúvidas não existem sobre a condição elementar que merece o direito à alimentação para fins de satisfação deste "direito primevo". Direitos de cunho liberal, social, econômico e ou cultural não são suportados efetivamente quando seus titulares definham, pela fome ou por condições precárias de nutrição. Pensar diferente significará crer na existência de um sujeito de direito sem direitos. Nos dizeres de Shiva, o mais básico dos Direitos Humanos hoje é o direito ao alimento (2003, p. 89).

Efetivamente, nesta quadra, torna-se válido ultrapassar o significado dos Direitos Humanos, manejado para direitos que se dizem universais e relacionados com a dignidade da pessoa humana. Ainda que em princípio, seu advento esteja vinculado com pretensões morais justificadas, não necessariamente derivadas de concessões amistosas por parte dos Estados, o que se demanda nos tempos atuais é justamente a compreensão da universalidade dos Direitos Humanos enquanto instituto efetivo, para além de definições.

Assim, a elevação das pretensões jurídicas acerca dos alimentos, provem de

processo que se estende por décadas, possuindo como linha indutora, para satisfação R. Fac. Dir. UFG, v. 40, n.1, p. 96 - 120, jan. / jun. 2016 
substancial de tal direito, o foco em questões globais, articulando mecanismos estatais, regionais, internacionais, de cunho público, privado e/ou do terceiro setor, para respeito, proteção, facilitação e providências relativas à segurança alimentar, alimentos e erradicação da fome, tal qual assevera o Plano de Ações do World Food Summit, de 1996. Como consequência, a reunião de múltiplos atores comungando dos mesmos desideratos propiciaram o enquadramento do direito à alimentação como obrigação legal e/ou negocial. Consequentemente, o movimento de reconhecimento em nível global do direito à alimentação acaba por estabelecer diretrizes up-down que incidem nos respectivos estados nacionais, a exemplo dos Estados Unidos da América, Índia, Brasil, Quênia e outros (KENT, 2010, p. 4).

Ainda que casos esporádicos possam ser analisados no sentido inverso, isto é, do nacional para o global/transnacional, maior espaço de externalização de problemas e demandas pelo alimento sedimentam-se progressivamente em níveis transnacionais. Inclusive, com líderes nacionais que projetam para além de seus territórios geopolíticos pretensões deste gênero. Indiretamente, significa isto sim, que há uma real percepção da debilidade estatal para enfrentamento de um problema que não reconhece fronteiras ou nacionalidades.

Não faz mais sentido crer que o desejo de consumir alimentos sadios se conserva apenas no âmbito individual e subjetivo de cada pessoa (TELESETSKY, 2013-2014, p. 492). Tal comportamento repercute diretamente, de forma conectada, na vida de milhões de pessoas nos diversos quadrantes do planeta, muitos dos quais almejam sobreviver unicamente. Segundo dados da FAO, aproximadamente 100 milhões de pessoas têm dificuldades para alimentar-se adequadamente, com destaque para quarenta países que registram consequências da desnutrição, embora, não haja relação direta destes dados com carência de recursos naturais em cada uma destas nações.

Para fins de ilustração desta passagem de transferência da centralidade do eixo político nacional para espaços de governança global torna-se válido o discurso de Nicolas Sarkozy, em fevereiro de 2011, na cidade de Addis Abeba, enquanto presidente francês. Nesta ocasião, Sarkozy manifestou-se no sentido de propor aos países industrializados e em via de desenvolvimento a regularem as transações de matérias primas (commodities), em uma clara demanda por posicionamento transnacional. Noutras palavras, o pleito do então presidente francês não se insere nas linhas do colonialismo, mas, na globalização de crises e pretensões que necessitam de atenção por parte do Direito, que não seja, contudo, sedimentado no aspecto nacional.

Além da discussão de fundo geopolítica, porém não menos importante, há no 


\section{A TUTELA JURÍDICA GLOBAL DA ALIMENTAÇÃO}

discurso de Sarkozy um ponto especial que merece abordagem. Trata-se de sua crítica em relação à libertinagem negocial das commodities que paulatinamente tem alterado substancialmente as premissas de segurança alimentar. Isto se deve ao fenômeno da especulação da agricultura e sua respectiva expansão em cifras financeiras negociadas em bolsas de valores que suprime a condição de subsistência milenar para inseri-la no ciberespaço do mundo financeiro. Não se cultiva mais, o que se faz é instituir um sistema que torce simplesmente pelo aumento dos preços dos alimentos. O eixo saiu do campo para estar nos bancos e instituições financeiras transnacionais, que projetam um cenário futuro pautado pela especulação e concentração de mercado (SCHUMANN, 2014).

De acordo com estudos da FAO, desde 2000, os preços negociais transnacionais dos alimentos podem ser mirados em uma linha progressivamente ascendente, salvo o período de 2008, em consequência da crise nos Estados Unidos e Europa. Descontada a média da inflação, considerando a última década, o Relatório de 2012, aponta a duplicação real dos valores dos alimentos essenciais para a alimentação humana, com o detalhe que onera demasiadamente os países periféricos, se comparado aos estados europeus, norte-americanos e australiano. Assim, a Argentina, enquanto um dos maiores produtores de cereais mundiais, tem, proporcionalmente, valor efetivamente superior as mesmas substâncias genuínas desta, mas vendidas na Alemanha, por exemplo. Contudo, em tal país europeu, em média a população gasta $10 \%$ de sua renda mensal com alimentação, enquanto nos países tradicionalmente produtores esta cifra é largamente mais comprometedora.

As últimas décadas foram determinantes na completa alteração de fluxo dos mercados, notadamente após a revogação da Lei Glass-Steagall e da Lei Gramm-LeachBlilley, nos idos de 1930. A primeira ampliou para além do espectro financeiro as atividades bancárias. A segunda possibilitou indiretamente a livre contratação de negócios futuros. A condição transnacional de bens e serviços possibilitou a transformação do mercado de matérias primas. Em comum, ambas as medidas em solo americano, no intuito de liberalizar o mercado estabeleceram premissas anarquistas. Essa virada criou uma estrutura perversa de formação dos preços sobre as commodities e proteção das volatilidades do mercado. Como consequência, nos dizeres de Harald Schumann, o que se procede desde então é aposta desenfreada da evolução dos preços das matérias primas (SCHUMANN, 2014, p. 89-90).

A força motriz do sistema de gêneros alimentícios, especialmente commodities, não se sedimenta no cultivo e produção. O que se percebe, embora os dados sejam velados, é uma constante destinação do mercado para estocagem, especulação e concentração deste em 
poucos, porém, gigantescos fundos de investimento. De acordo com dados noticiados pela Comissão de Transações de Mercado de Futuros e Matérias Primas, o volume de commodities negociadas em bolsas e mercados extra-bolsas é substancialmente superior pela multiplicação (não pela adição!) à capacidade de produção agrícola mundial. Ato continuo, este super ciclo promove a alta do petróleo, não por sua relação como fonte de energia, mas insumo para a agricultura, que retroalimenta o avanço do preço das commodities (logo, dos alimentos) em uma verdadeira espiral ascendente infinita, conforme se vislumbra com os acontecimentos de econômicos de 2008.

Nesta senda, curiosa é a manifestação de Chilton (2011), ao retratar a posição de membros da Future Industry Association, para quem não concordam com a premissa de que especuladores controlam os preços dos alimentos, mas que apertam o acelerador de modo progressivo. Isto é, a clássica relação oferta-demanda como determinante de preços é substituída pela centralidade na especulação em mercados futuros pautados por psicologias de massa com orientação no estilo "quanto pior, melhor".

Exemplo cabal pode ser extraído do episódio referente às reservas russas de trigo. O verão de 2010 produziu uma quebra significativa da safra deste grão no território russo. Como medida de proteção dos preços em seu território, Vladimir Putin proibiu a exportação do cereal, em 2011, imediatamente o que se sucedeu foi a queda do preço do trigo na ordem de $50 \%$, bem como, o afastamento do risco do desabastecimento, pois as estimativas de suas reservas foram ultrapassadas em 20 mil toneladas.

Outra consequência deste comportamento, surge da impossibilidade de controle sobre a inflação, justamente pela razão óbvia de que sua existência aumenta o lucro dos especuladores, além dos tradicionais argumentos de esgotamento das áreas cultiváveis versus demasiado incremento demográfico, bem como desastres e desequilíbrios ambientais cada vez mais frequentes. Todos estes fatores, somados a ausência de regulamentação, projetam todos os preços futuros para níveis surreais.

Assim, todo o quadro trágico pintado fundamenta-se na tendência instalada de estocagem e armazenamento commodities, especialmente de gêneros alimentícios. Eis a tragédia: não se cultiva para se comercializar na forma de alimento, direto ou indireto, mas, sim, para se especular e inflacionar crises essencialmente humanitárias. Isso explica a quantidade de silos que brotam no campo.

Contudo, a estocagem de alimentos para especulação sobretudo, depois, a comercialização concentrada em grandes grupos financeiros apresenta outro fato insidioso: a 


\section{A TUTELA JURÍDICA GLOBAL DA ALIMENTAÇÃO}

condição de dependência da produção de outros gigantescos conglomerados que detém patentes e royaltes sobre sementes, insumos e implementos de modo efetivamente cogente. Não por acaso, o cultivo de alimentos tenha deixado de ser uma necessidade universal para converter-se em privilégios de poucos. Ontem, a agricultura, hoje, o agrimoney.

Todas essas situações fazem com que a cada ciclo de duas ou três safras, a partir de 2008, a voracidade dos especuladores produza um contingente de 100 mil indivíduos que não conseguem acompanhar com suas rendas o custo da subsistência alimentar, segundo dados do Banco Mundial e da Conferência das Nações Unidas sobre Comércio e Desenvolvimento (2011).

Por fim, não parece prudente atribuir toda a responsabilidade deste cenário na conta da globalização e dos seus múltiplos estratos. De fato, há um contributo que pode ser contextualizado na facilitação de bens, serviços e capitais. Basta pensar que em tempos passados o mesmo intuito de usura de viveres fora detectado na Grécia antiga. Contudo, onde se deposita o veneno também pode estar o antídoto. Qualquer tentativa de equalização de condições adequadas, sob a óptica do acesso à alimentação, somente logrará êxito se instituída em nível global, mediante instrumentos de governança e regulação normativo-negocial. Ao tempo em que a pretensão por alimentos é inerente à existência biológica humana e não política, bem como, a força de concentração dos mercados especulativos escapa do controle estatal, não faz sentido repetir velhas formas de regulação nacional, desde início impotentes, frente a atual conjectura.

Não parece ser factível defender ideais de dignidade da pessoa humana, democracia, desenvolvimento sustentável, sustentabilidade e afins se a premissa básica condicionante da existência humana que é a alimentação adequada não restar tutelada, seja por políticas ou regulações globais, independentemente de qualquer requisito ou condição.

\subsection{Regime Global para o Direito à Alimentação}

$\mathrm{Na}$ medida em que pretensões dos mais diversos níveis se globalizam, proporcionalmente o Direito deve atentar-se para cumprir com seu desiderato básico, representado na limitação dos poderes. Assim, se o reconhecimento formal do direito à alimentação adequada não é garantia de sua adimplência, seja por impotência dos tradicionais atores frente aos novos desafios ou pelo agigantamento e fluidez do mercado, o passo seguinte que deve ser tracejado é o enfrentamento destes problemas nos espaços em que ocorrem, R. Fac. Dir. UFG, v. 40, n.1, p. 96 - 120, jan. / jun. 2016 
superando discursos e práticas maniqueístas.

Significa argumentar que a tutela efetiva do direito à alimentação deve ser priorizada em níveis transnacionais, mediante um regime global. Note-se que isoladamente tal proposta não terá maiores chances de êxito. Também não basta se fixar na crítica à globalização, somente pela crítica, com argumentos de cunho unicamente nacionalista. O que se defende é diretrizes globais, de cunho normativo e negocial, que consigam vincular também ações nacionais, internacionais e comunitárias, sob pena de se fazer mais do mesmo. Em sendo o direito à alimentação Direito Humano, o referencial que necessita ser destacado é justamente a condição humana, independentemente de atributos de nacionalidade. Logo uma rígida regulamentação nacional ou comunitária sobre o acesso à alimentação pode, noutro flanco, precarizar o que já é precário em determinados locais ou instalar um regime de dumping alimentar (caso da Argentina em relação a União Europeia e Estados membros).

Para tanto, nesta quadra surge com relevância o desafio de se promover mecanismos efetivos de governança transnacional/global para debelar os problemas existentes justamente pela parca regulação em cenários transnacionais (LAMBERT, 2012, p. 04). O posicionamento de instrumentos de governança em múltiplos níveis e de forma articulada pode obter sucesso maior que o obtido pelas ações em curso, sedimentadas na dependência dos Estados nacionais.

É preciso que tais práticas de governança envolvam medidas de regulação normativa e negocial. Parece de baixa capacidade de realização acreditar que se possa avançar em níveis positivos, em um campo de ação privativamente negocial, sem se valer de expedientes negociais, validados por procedimentos de consensualidade, tal qual se caracteriza o Direito Global.

$\mathrm{O}$ advento do transnacionalismo e da globalização jurídica apresenta em sua essência traços de consensualidade, na faceta de contratos, acordos, cooperações, mútuo reconhecimento nos expedientes de produção normativa e, por sua vez, negociações, mediações, conciliações e arbitragem para a resolução das controvérsias. Ainda que se possa elencar instituições transnacionais para resolução de pretensões resistidas, aos moldes de tribunais, todavia, sua constituição não escapa dos convênios marcos, ou seja, da consensualidade. Em linhas gerais, não há espaço no atual panorama para uma autoridade global suprema, aos moldes do paradigma nacional e das tradições institucionais judaicocristãs (STAFFEN, 2015, p. 34-36).

Nesta quadra, importante abrir uma brecha para a análise de categoria relegada em 


\section{A TUTELA JURÍDICA GLOBAL DA ALIMENTAÇÃO}

plano inferior em comparação à governança. Trata-se justamente da relevância a ser atribuída à consensualidade, enquanto mecanismo decisional interessado na não-ocorrência de contestação da solução pelas partes sujeitas à resolução dos conflitos, fazendo frente aos desafios da unanimidade (CASSESE, 2013, p. 31). Observa-se a guinada em favor da consensualidade na Conferência das Nações Unidas sobre Comércio e Desenvolvimento, Acordo Internacional sobre Azeite de Oliva e Comitê para a Proteção Ambiental.

Em contraponto, consensualidade e governança se complementam reciprocamente na medida em que colaboram para favorecer a funcionalidade deste network transnacional. Criam-se procedimentos administrativos mediante acordos para governabilidade cooperativa, via coligações que mesclam o nacional com o propósito de constituir o global (transnacional) (SLAUGHTER, 2000, p. 192-ss).

Estabelecendo um cenário hipotético, no qual o critério determinante será a predominância da força, qualquer tentativa nacional de consolidar normas nos moldes tradicionais para assegurar o direito à alimentação, brecando os fluxos de mercado, descambará em um bloqueio econômico não declarado que se prestará para precarizar as condições locais, de modo que não há possibilidade de sustentação de medidas deste gênero fechadas à globalização. Noutro cenário, na hipótese de se dispensar o diálogo e a consensualidade simplesmente pela inexistência de limites normativos (regulação/negociação), isto é, implantação de autonomia anárquica do mercado especulativo retroalimentaria o contexto inaugurado a partir de 1930.

Diante deste desafio diversos líderes mundiais, representando várias instituições principiaram o debate sobre duas linhas estruturantes: a) regulamentar o ímpeto do mercado especulativo de commodities, justamente pelo terrorismo que incentivam e sobre o qual lucram e: b) organizar um Códex Alimentarium, comprometido com a fixação de níveis seguros de acesso à alimentação adequada, informada e consciente.

Conforme já consignado, um dos link cases pode ser visualizado na manifestação de Nicolas Sarkozy, o qual além da questão alimentícia, associou o atual momento como gerador de graves riscos à paz e à democracia. Sarkozy aproveitou o ano de 2011, quando cumulou a presidência da França com a direção do G-20 para pautar o controle da especulação sobre os alimentos como uma das três prioridades do bloco. De imediato, o que deve ser destacado é justamente a pauta exposta em nível transnacional, com argumentos transnacionais, sobre uma demanda que é global e condição de sustentabilidade do planeta. Certamente, não se trata de mera coincidência política. Entretanto, as propostas neste caso não 
avançaram na intensidade necessária pela postura protecionista de países como Austrália, Canadá, Brasil, Argentina, Uruguai, Chile e Bolívia, muito embora depois a presidente Dilma Rousseff tenha reconhecido os riscos humanitários da especulação sobre os preços dos alimentos, por pressão dos BRICS, em 2011.

Igual compromisso ético fora assumido pelo Parlamento Europeu, Conselho dos Ministros e Comissão Europeia que tratou de avaliar e implementar meios de regulamentar a matéria por meio de Diretivas, reverendo, inclusive, o teor da Diretiva sobre Abuso de Mercado e a Diretiva MiFID (Markets in Financial Instruments Directive). Outras iniciativas são alocadas de forma específica no European Market Infrastructure Regulation (EMIR). Em comum, todas as medidas visam colocar sobre vigilância as operações de especulação no mercado financeiro europeu, ou praticado por pessoa física e/ou jurídica residente/sediada nos Estados membros europeus em qualquer outro mercado; limitar a atuação de fundos de investimentos, bancos e companhias de seguro na fixação de preços de artigos de primeira necessidade, estabelecendo, se for o caso, estratos determinados para atuação através de contratos futuros. Aqui, a oposição deriva de segmentos bancários alemães e do governo britânico.

Especificamente no contexto normativo europeu, interessante destacar que, embora suas Diretivas tenham força cogente nos respectivos Estados membros, paralelamente acabam por estabelecer critérios jurídicos para além do seu espaço comunitário. Assim, seriam medidas válidas e efetivas de limitação dos poderes que se deslocam globalmente, mas que em dado momento, contatam com a União Europeia.

Os Estados Unidos por sua vez, que outrora erradicaram com os freios no mercado futuro de matérias primas, a partir de uma postura clara do presidente Barack Obama, se envolveram no debate e, por meio da Lei Dodd-Franck, restauram os freios e contrapesos anteriores ao sistema especulativo americano, porém capaz de impactar em todos os locais do globo, tanto por força da atuação de seus especuladores, assim como, pela centralidade que a Bolsa de Chicago possui na negociação de commodities. Contudo, a iniciativa resta embaraçada por expedientes burocráticos que encolhem com os resultados desejados.

Outros casos podem ser destacados em vários organismos de impacto transnacional/global, tais como a Organização Mundial do Comércio, Organização dos Estados Americanos, do World Business Council for Sustainable Development perante governos, organizações internacionais e organizações não-governamentais para promoção de 


\section{A TUTELA JURÍDICA GLOBAL DA ALIMENTAÇÃO}

políticas de desenvolvimento sustentável e correlatos. Noutro campo, os atores transnacionais passam a ter responsabilidade direta na promoção dos Direitos Humanos, tal qual consignado no Guidelines for Multinational Enterprises (MASTAGLIA, 2007), inclusive, com o dever do Órgão de Solução de Controvérsias, da OMC, em apreciar o respeito do direito à alimentação.

Por sua vez, a segunda linha de atenção, deve orientar a pauta global de regulação dos alimentos que incindirá sobre o Codex Alimentarius e os Sistemas Nacionais de Controle Alimentar. Ao tempo em que não restam dúvidas sobre todos os fluxos e influxos da globalização necessário se faz estabelecer premissas sólidas e sustentáveis ao comércio de alimentos referenciando o marco jurídico transnacional, no momento de alinhar mecanismos regionais e nacionais (FOOD AND AGRICULTURE ORGANIZATION, 2006, p. 22).

Assim, mesmo que exista determinada parcela de autonomia dos Estados nacionais para instituírem seus parâmetros locais de regulação sobre os alimentos, há um movimento fático e progressivo que, sob a liderança da OMC, junto com a FAO e a OMS, visa estabelecer diretrizes, bem como, instâncias de solução de controvérsias, em espaços de regulação global, em um típico exemplo de governança, interessado em promover um alinhamento global dos estandartes (MARICHAL, 2014, p. 309).

Em comum, observa-se uma convergência nos textos para abordagens gerais (horizontais) e, noutros casos, especificas (verticais), conforme a necessidade da matéria, com requisitos detalhados sobre determinado tipo de alimento ou grupos de alimentos, informações sobre o processo de manipulação/produção e inocuidades para fins de tutela dos consumidores. Eis que se materializa o primado da informação, afinal, desde seu nascedouro em 1991, essa assinalava como função principal a formalização de bases científicas sobre a normatização da segurança alimentar, enquanto pressuposto do Direito Global.

Como consequência, ao fixar padrões de segurança alimentar, com a participação de atores e expedientes de governança global, os regramentos do Codex Alimentarius convertem-se em preceitos de força cogente, via Acordo sobre Medidas Sanitárias e Fitossanitárias, da OMC, cuja uniformidade assegura maior fluidez e racionalidade ao comércio mundial de alimentos, servindo de ponto de referência internacional "invisível", porém, efetivo (WINICKOFF; BOUSHEY, 2010).

Entretanto, importante atestar que tais diretrizes descritas no Codex Alimentarius, além da vocação informativa da avaliação, gestão e comunicação dos riscos, possuem mecanismos sólidos de correição dos instrumentos nacionais, constituindo-se, verdadeiramente, de sistema de via única, que impede a invocação de questões de diversidade 
cultural que poderiam ser utilizadas para além do seu contexto, as quais neutralizariam os objetivos nodais da proposta. ${ }^{6}$

Em síntese, a satisfação dos propósitos do Codex Alimentarius ganha facticidade nos vários cenários do complexo regime multilevel da globalização quando, determinados produtos passam a receber atenção específica, especialmente, pelas fórmulas e ingredientes que os compõem, pautando-se, sempre, pela descrição dos riscos que portam, bem como, por medidas concretas de mitigação dos mesmos. Para tanto, cite-se a preocupação com a utilização de determinadas gorduras, proteínas, sódio, conservantes e afins, os quais não são descritos nos rótulos por mero acaso. Por esse motivo, a relevância da normatização global não se resume no direito à alimentação, e, sim, na padronização de alimentos adequados para o consumo humano, seguindo padrões inter-geracionais sustentáveis para sua produção, comercialização e destinação.

\section{CONSIDERAÇÕES FINAIS}

Nos termos alhures consignados o que necessita ser extraído com máxima clareza e, portanto, reafirmado é a elementar compreensão e aplicação integral do direito à alimentação adequada em cenários que não se pautem somente por atributos de nacionalidade e/ou cidadania. Logo, as pretensões jurídica e moralmente justificadas devem ser adimplidas em razão da condição humana essencialmente, a qual é preexistente a qualquer outra adjetivação de ordem política.

A alimentação, neste norte, carece de ser tutelada como interesse sem precedentes, genuinamente humano, isto é, não pendente de justificativas para sua pretensão. Verdadeiro Direito Humano essencial. Por sua vez, em espaços cada vez mais tomados pela globalização e suas múltiplas facetas, a demanda que se apresenta não pode ser reduzida aos limites fronteiriços de Estados nacionais e/ou blocos comunitários. Ao tempo em que o problema constrange o mundo, o mundo deve dedicar todos os esforços para o tratamento desta crise que se arrasta por séculos.

Para melhor enfrentamento, duas operações devem agir de modo coordenado: primeiro, para assegurar condição adequada de alimentação para todos, regulando, inclusive, o mercado transnacional de matérias primas notadamente concentrado e especulativo, que lucra com o medo e evidências de crises humanitárias, climáticas, políticas e econômicas; segundo, estabelecendo estandartes políticos e normativos globais para fixação de níveis 


\section{A TUTELA JURÍDICA GLOBAL DA ALIMENTAÇÃO}

seguros de produção e comercialização de gêneros alimentícios.

Enquanto essas demandas não ocorre(re)m, qualquer discurso responsável sobre Democracia, torna-se artificial e dramático. Afinal, quando o mais elementar dos direitos não é garantido adequadamente todos os demais restam mitigados e obstaculizados. Ademais, tanto a concentração do mercado de matérias primas no portfólio especulativo de uma dezena de corporações transnacionais, bem como, a constante ameaça da forme faz com que o ideal de Democracia seja esvaziado.

Simultaneamente, a própria efetivação da Sustentabilidade e seus preceitos devem transpor os desafios da fome e da crise alimentar instalada. Basta rememorar os Objetivos de Desenvolvimento do Milênio e os Objetivos do Desenvolvimento Sustentável, frutificados a partir do discurso da Sustentabilidade, cujo pacto primeiro é a erradicação da miséria, simbolizado pela pobreza de gêneros alimentícios. Ao passo, que há um real descontrole nos meios de produção, comercialização e consumo de alimentos, nas margens da anarquia em alguma medida, o resultado de tal retrato expõe essencialmente a insustentabilidade do sistema operante, sem preocupações solidárias de índole social, ecológica, econômica, tecnológica e humanitária, nos dizeres de Telesetsky (2013-2014). Breca, isto sim, a adoção de expedientes sustentáveis e democráticos para efetivação do acesso à alimentação adequada e universal.

Por essas razões, deste objetivo não pode se furtar o Direito Global, justamente pelas relações diretas existentes com práticas de globalização dos riscos e das pretensões jurídicas de contenção. Problemas globais devem, necessariamente, ser sanados por ações globais, com reflexos locais, regionais, nacionais e internacionais, o que significa dizer que o Direito Global não deve assumir a primazia desta nau, mas balizar políticas globais de planejamento, normatização e correição a fim de mitigar as desigualdades no mundo as quais impedem, por exemplo, a chance de uma vida qualitativa por meio da alimentação. Há uma imperiosa necessidade de políticas perenes e efetivas para tais direitos, não apenas direitos.

\section{REFERÊNCIAS}

AQUINO, Sérgio Ricardo Fernandes. O direito em busca de sua humanidade: diálogos errantes. Curitiba: CRV, 2014.

ARNAUD, André-Jean. Governar sem fronteiras. Entre globalização e pós-globalização. Rio de Janeiro: Lumen Juris, 2007. 
CANOTILHO, José Joaquim Gomes. "Brancosos" e interconstitucionalidade. Itinerários dos discursos sobre a historicidade constitucional. Coimbra: Almedina, 2008.

CASSESE, Sabino. Chi governa il mondo? Bologna: Il Mulino, 2013.

CASSESE, Sabino. Oltre lo Stato. Bari/Roma: Laterza, 2006.

CHILTON, Bart. Opening remarks to the Futures Industry Association's panel discussion: financial investor's impact on commodity prices. Boca Raton, 16 mar. 2011.

CONFERÊNCIA DAS NAÇÕES UNIDAS SOBRE COMÉRCIO E DESENVOLVIMENTO. Price formation in financialized commodity markets: the role of information. Genebra, jun. 2011.

COTTERRELL, Roger. Law, culture and society. Aldershot: Ashgate, 2006.

COTTORRELL, Roger. What is transnational law? Law \& Social Inquiry - Queen Mary University of London, London, n. 2, p. 340-372, 2012.

CROUCH, Colin. Postdemocrazia. Roma-Bari: Laterza, 2005.

FOOD AND AGRICULTURE ORGANIZATION. Diretrices en materia de legislación alimentaria (nuevo modelo de ley de alimentos para países de tradición jurídica romanogermânica). Roma: FAO, 2006.

FUKUYAMA, Francis. O fim da história e o último homem. Rio de Janeiro: Rocco, 1992.

GIUDICE, Alessio lo. Istituire il postnazionale. Identità europea e legittimazione. Torino: G. Giappichelli, 2011.

GROSSI, Paolo. Mitologie giuridiche della modernità. 3. ed. Milano: Giuffrè, 2007.

GRUBBA, Leilane Serratine. O problema do essencialismo no direito: inerentismo e universalismo como pressupostos das teorias que sustentam o discurso das Nações Unidas sobre os direitos humanos. Florianópolis. Tese apresentada ao Programa de Pós-Graduação em Direito. Curso de Doutorado. Universidade Federal de Santa Catarina, 2015.

JESSUP. Philip. Direito transnacional. Rio de Janeiro: Fundo de Cultura, 1965.

KENT, George. The human rigth to food and dignity. Human Rigth, v. 02, 2010.

KINGSBURY, Benedict; KIRSCH, Nico; STEWART, Richard. The emergence of global administrative law. Law and Contemporary Problems. V. 38, n.3/4, p. 20, 2005.

LAMBERT, Hélène. Transnational law, judges and refugees in the European Union. GOODWIN-GILL, Guy S.; LAMBERT, Hélene. The limits of transnational law. Cambridge: Cambridge University Press, 2012.

LEEBRON, David W. Linkages. American Journal of International Law. Yale: v. 96, 2002. 
MARICHAL, Maria Eugenia. La OMC y el proceso de globalización de la regulación alimentaria. Revista de Direito Internacional, Brasília, v. 12, n. 2, 2014, p. 306-320.

MASTAGLIA, Gabriela Teresita. Globalización y desarrollo: su impacto en el ámbito de los derechos humanos. BARRAL, Welber; CORREA, Carlos. Derecho, desarrollo y sistema multilateral del comercio. Buenos Aires/Florianópolis: Fundação Boiteux, 2007.

OLIVIERO, Maurizio; CRUZ, Paulo Márcio. Reflexões sobre o direito transnacional. Revista Novos Estudos Jurídicos. Itajaí, v. 17, n. 1, p. 18-28, 2012.

REPOSO, Antonio. Introduzione allo studio del diritto costituzionale e pubblico. PEGORARO, Lucio; REPOSO, Antonio; RINELLA, Angelo; SCARCIGLIA, Roberto; VOLPI, Mauro. Diritto costituzionale e pubblico. 3. ed. Torino: G. Giappichelli, 2009.

ROSA, Alexandre Morais da. Garantismo jurídico e controle de constitucionalidade material. Florianópolis: Habitus, 2002.

ROSENAU, James N.: CZEMPIEL, Ernst Otto. (Orgs.). Governance without government: order and change in world politics. Cambridge: Cambridge University Press, 1992.

SCHEPEL, Harm. The constitution of private governance: product standards of integrating markets. Oxford: Hart, 2005.

SCHUMANN, Harald. Especuladores del hambre. Por qué suben los alimentos? Buenos Aires:Mardulce, 2014.

SHIVA, Vandana. Food rigths, free trade and fascism. GIBNEY, Matthew J. (Ed.). Globalizing rigths: The Oxford Amnesty Lectures 1999, Oxford: Oxford University Press, 2003.

SLAUGHTER, Anna-Marie. Governing the global economy through government network. BYERS, M. (Org.). The rule of law in international politics. Oxford: Oxford University Press, 2000.

SNYDER, Francis. Governing economic globalization: global legal pluralism and european law. European Law Journal, 5/4, 1999.

STAFFEN, Márcio Ricardo. Interfaces do direito global. Rio de Janeiro: Lumen Juris, 2015.

STAFFEN, Márcio Ricardo; BODNAR, Zenildo; CRUZ, Paulo Márcio. Transnacionalización, sostenibilidad y el nuevo paradigma de derecho in siglo XXI. Revista Opinión Jurídica Universidad de Medellín, v. 10, p. 159-174, 2011.

TEUBNER, Gunther et alii. Transnational governance and constitucionalism. Oxford: University Oxford Press, 2004.

TEUBNER, Gunther. El derecho como sistema autopoiético de la sociedad global. Bogotá: Universidad Externado de Colombia, 2005. 
TELESETSKY, Anastasia. Waste not, want not: the right to food, food waste and the sustainable development goals. The Denver Journal of International Law and Policy, v. 42, n. 3, p. 492, 2013-2014.

WINICKOFF, David; BOUSHEY, Douglas. Science and power in global food regulation: the rise of the Codex Alimentarius. Science, Technology \& Human Values, v. 35, n. 3, 2010, p. 356-381.

\footnotetext{
${ }^{1}$ Sobre tais circunstâncias ver: REPOSO, 2009, p. 24 e ss.

${ }^{2}$ Merece reprodução nesta quadra a advertência de Cassese: "Infine, il transnazionalismo dell'ordine giuridico globale suggerisce cautela nel parlare di crisi dello Stato e di fuga verso il livello globale, perchè la dinamica del sistema amministrativo globale è largamente dipendente dallo Stato o da suoi frammenti." (2006, p. 12-13).

${ }^{3}$ Nestes termos: "Le grandi multinazionali hanno spesso superato la capacità di amministrazione dei singoli Stati nazionali. Se non apprezzano il regime fiscale o normativo in un Paese, esse minacciano di trasferirsi altrove e gli Stati entrano sempre più in competizione fra loro nella disponibilità di offrire condizioni favorevoli, poichè hanno bisogno di quegli investimenti." (CROUCH, 2005, p. 35).

${ }^{4}$ Em complemento: "Il diritto globale, quindi, non si forma solo attraverso un processo di diffusione unidirezionale, dal livello superiore al livello inferiore (top- $d w n$ approach), ma anche com un percorso inverso, che procede dal basso verso l'alto (bottom-up approach). Le norme nazionali possono essere recipete e «risalise» a livello sovranazionale". (CASSESE, 2009, p. 125).

${ }^{5}$ Sobre tal tema recomenda-se a leitura de Grubba, 2015.

${ }^{6}$ MARICHAL, Maria Eugenia. La OMC y el proceso de globalización de la regulación alimentaria. Revista de Direito Internacional, Brasília, v. 12, n. 2, 2014, p. 315.
}

Artigo recebido em 19 de outubro de 2015 e aceito em 12 de janeiro de 2016 